\title{
Plume Parameters and Thruster Properties of a Low Power Arcjet
}

\author{
Wenxia Pan*, Xian Meng, Heji Huang and Chengkang Wu \\ Institute of Mechanics, Chinese Academy of Sciences, Beijing 100190, China \\ (*wxpan@imech.ac.cn)
}

\begin{abstract}
A low power arcjet-thruster of $1 \mathrm{~kW}$-class with gas mixture of $\mathrm{H}_{2}-\mathrm{N}_{2}$ or pure argon as the propellant is fired at a chamber pressure about $10 \mathrm{~Pa}$. The nozzle temperature is detected with an infrared pyrometer; a plate set perpendicular to the plume axis and connected to a force sensor is used to measure the thrust; a probe with a tapered head is used for measuring the impact pressure in the plume flow; and a double-electrostatic probe system is applied to evaluate the electron temperature. Results indicate that the high nozzle temperature could adversely affect the conversion from enthalpy to kinetic energy. The plume flow deviates evidently from the LTE condition, and the rarefied-gas dynamic effect should be considered under the high temperature and low-pressure condition in analyzing the experimental phenomena.
\end{abstract}

Keywords: thruster properties, nozzle temperature, impact pressure, electron temperature.

\section{INTRODUCTION}

Electric propulsion is playing an increasingly important role in satellite propulsion, due to its high specific impulse which results in less propellant consumption or more payload under a given loading constraint of satellites. With a simple acceleration principle of heating up propellant by an arc discharge and converting the enthalpy into kinetic energy through nozzle expansion, the direct current (DC) arcjet thruster is characterized by system compactness and low development cost, employing hydrazine as propellant. In addition, arcjet propulsion usually has moderate thrust level, high thrust-to-power ratio beyond $100 \mathrm{mN} / \mathrm{kW}$ and specific impulse of $450-1000 \mathrm{~s}$ depending on the available power and propellant type. These make the arcjet thruster one of the most practical technologies for north-south station-keeping of communication satellites [1]. Research efforts on the performance of arcjet thruster and related physics are continuing for developing various special applications of different power levels, propellant types and working situation [2-5].

In the present work, properties of an arcjet thruster are evaluated experimentally by measuring its thrust and plume parameters. By analyzing the measured results, energy conversion efficiency in the nozzle and the state of the plume deviating from the local thermal equilibrium (LTE) condition are discussed preliminarily.

\section{EXPERIMENTAL CONDITIONS AND DATA ANALYZING METHODS}

A $1 \mathrm{~kW}$-class arcjet thruster is set in a vacuum chamber of $2 \mathrm{~m}$ diameter and $4 \mathrm{~m}$ length as shown in Fig.1. The pumping system is capable to keep the chamber pressure at lower than $10 \mathrm{~Pa}$ while a propellant of $5 \mathrm{slm}$ is fed. Gas mixture of $\mathrm{H}_{2}-\mathrm{N}_{2}$ or pure argon is used as the propellant. The thruster is fixed on a three-dimensional movable stage driven accurately along the plume axial and radial directions by stepping motors. The temperature of the nozzle outside wall is monitored with an infrared pyrometer of working range $600{ }^{\circ} \mathrm{C}$ to $2000{ }^{\circ} \mathrm{C}$, while the emission coefficient of the nozzle surface was estimated to be 0.31 . A heat-resistant metal plate of $200 \mathrm{~mm}$ in diameter is set perpendicular to the plume axis, and is attached to a sensitive force transducer to receive the impact effect of the plume, by which the thrust produced in the arcjet firing is measured. Signals from the force sensor are sampled by a data acquisition and processing system. A water-cooled probe with a tapered head and a $0.9 \mathrm{~mm}$ hole in the tip center connected to a pressure sensor of $1 \mathrm{kHz}$ response is used for measuring the impact pressure in the plume flow.

A double-electrostatic probe system is applied to evaluate the electron temperature, according to the following equation:

$$
\left.\frac{d I_{D}}{d U_{D}}\right|_{I_{D}=0}=\frac{e}{k T_{e}} \times \frac{I_{i 01} \times I_{i 02}}{I_{i 01}+I_{i 02}}
$$

Where $I_{D}$ is the current passing through the probe, $U_{D}$ is the voltage between two probe wires, $e$ is elementary charge, $k$ is Boltzmann constant and $I_{i 01}$ and $I_{i 02}$ are ion saturation currents. In order to obtain the electron 
temperature, the value of $d U_{D} / d I_{D}$ at the zero current point and ion saturation currents of $I_{i 01}$ and $I_{i 02}$ are measured. The system mainly consists of a double-electrostatic probe, a boron nitride holder, a DC bias power supply, a sampling resistance and a data acquisition system. The probe is made of two individual copper wires of $0.8 \mathrm{~mm}$ diameter with $7 \mathrm{~mm}$ exposed length in the plume. The bias power offers a voltage transition from $-29 \mathrm{~V}$ to $29 \mathrm{~V}$ on the probe circuit, and the ion current is calculated according to the voltage collected across the resistance.

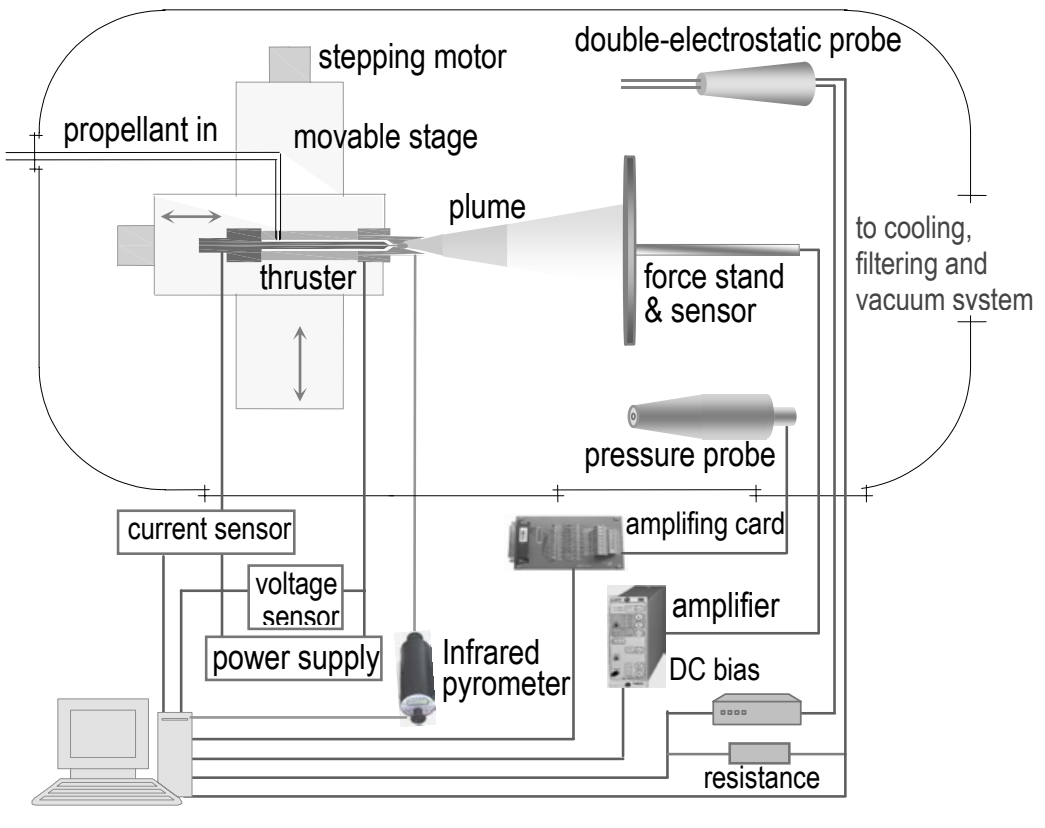

FIGURE 1. Schematic drawing of the experiamental setup.

\section{RESULTS AND DISCUSSIONS}

Figure 2 shows the measured time-dependent thrust (a) and nozzle temperature (b), under the constant working condition with gas mixture of $\mathrm{H}_{2}: \mathrm{N}_{2}=2.8: 1.5$ as the propellant at total flow rate of $35.4 \mathrm{mg} / \mathrm{s}$ and input power of 858 $\mathrm{W}$. The thrust efficiency and specific impulse are calculated according to the thrust, mass flow rate of the propellant and input power. As shown in Fig.2 (a), the thrust decreased slowly with increasing time, when input parameters were kept all unchanged, but the nozzle temperature as in Fig.2 (b) increased during the same time period. This indicates that the high nozzle temperature could adversely affect the conversion from high enthalpy state of archeated high-temperature gas to kinetic energy for producing thrust in the nozzle.
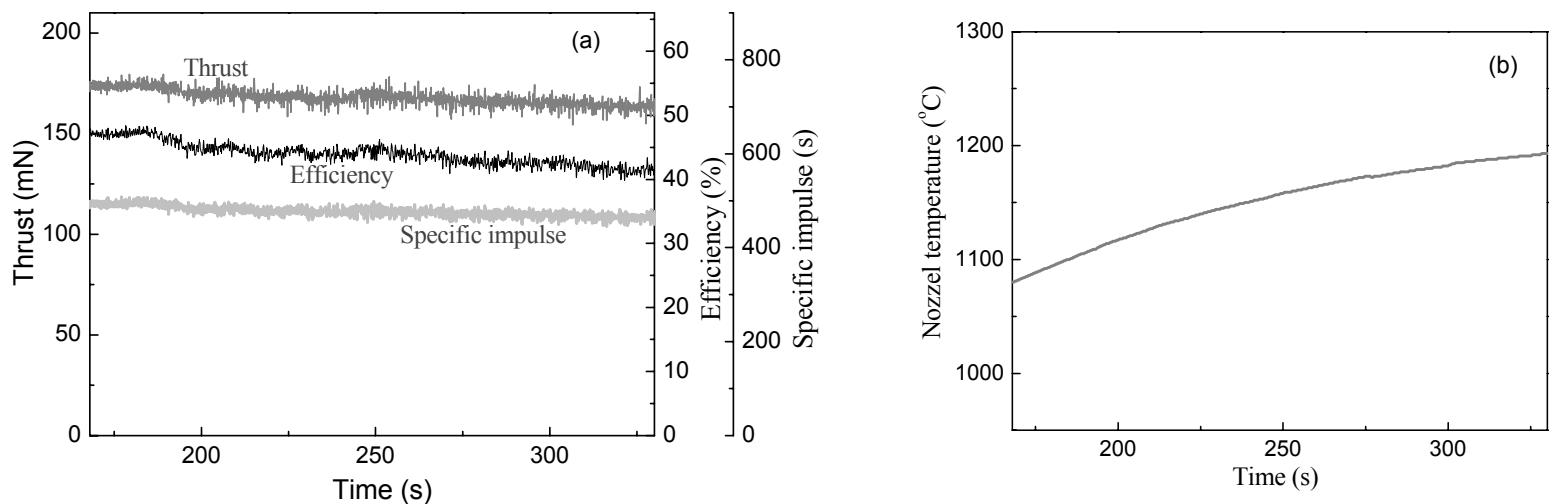

FIGURE 2. Variations of thrust, efficiency and specific impulse (a) and nozzle temperature (b) with firing time, with $\mathrm{H}_{2}+\mathrm{N}_{2}$ gas mixture at feeding rate of $35.4 \mathrm{mg} / \mathrm{s}$ as the propellant and input power of $858 \mathrm{~W}$.

The energy conversion situation occurring in the small nozzle cavity is quite difficult to be examined experimentally, due to its very narrow conic space shorter than $20 \mathrm{~mm}$ in axial direction and smaller than $11 \mathrm{~mm}$ in diameter with extremely high temperature and pressure gradients around $104 \mathrm{~K} / \mathrm{mm}$ and $104 \mathrm{~Pa} / \mathrm{mm}$, respectively. Plume parameters outside the nozzle could be examined more conveniently, those reflect to some extent the situation of energy conversion in the nozzle. Preliminary measurement and estimation show that the mean exhaust gas temperature is lower than $3000 \mathrm{~K}$ when argon was used as the propellant at flow rate of $100-270 \mathrm{mg} / \mathrm{s}$ and input 
power of 120-400 W, but its electron temperature is much higher as shown in Fig.3. This suggests that the plume flow deviates evidently from the LTE condition. Besides the exhaust heat loss, frozen flow loss exists even in the case in which atomic propellant of argon is fired.

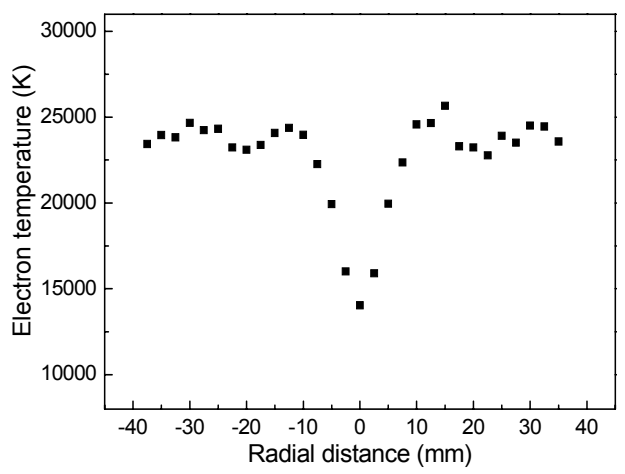

FIGURE 3. Radial distribution of the measured electron temperature at axial distance of $11 \mathrm{~mm}$ from the nozzle exit, with Ar propellant at feeding rate of $83.3 \mathrm{mg} / \mathrm{s}$ and input power of $210 \mathrm{~W}$.

Figure 4 (a) plots the radial distributions of the measured impact pressure in the plume with $\mathrm{H}_{2}: \mathrm{N}_{2}=2: 1$ as the propellant at feeding rate of $35.7 \mathrm{mg} / \mathrm{s}$ and input power of $900 \mathrm{~W}$. The maximum impact pressure is about $5200 \mathrm{~Pa}$ at the plume center $7.5 \mathrm{~mm}$ away from the nozzle exit, and it decreases to about $400 \mathrm{~Pa}$ at the axial distance of 37.5 $\mathrm{mm}$. Figure 4 (b) shows the impact pressure along the plume axis. The solid line and the dashed line are obtained by moving the thruster along the plume axis continuously at a speed of $5 \mathrm{~mm} / \mathrm{s}$, and circles is the maximum values in Fig.4 (a). Obtained in about 10 minutes, results in Fig.4 (b) indicate the stable working situation of the arcjet thruster
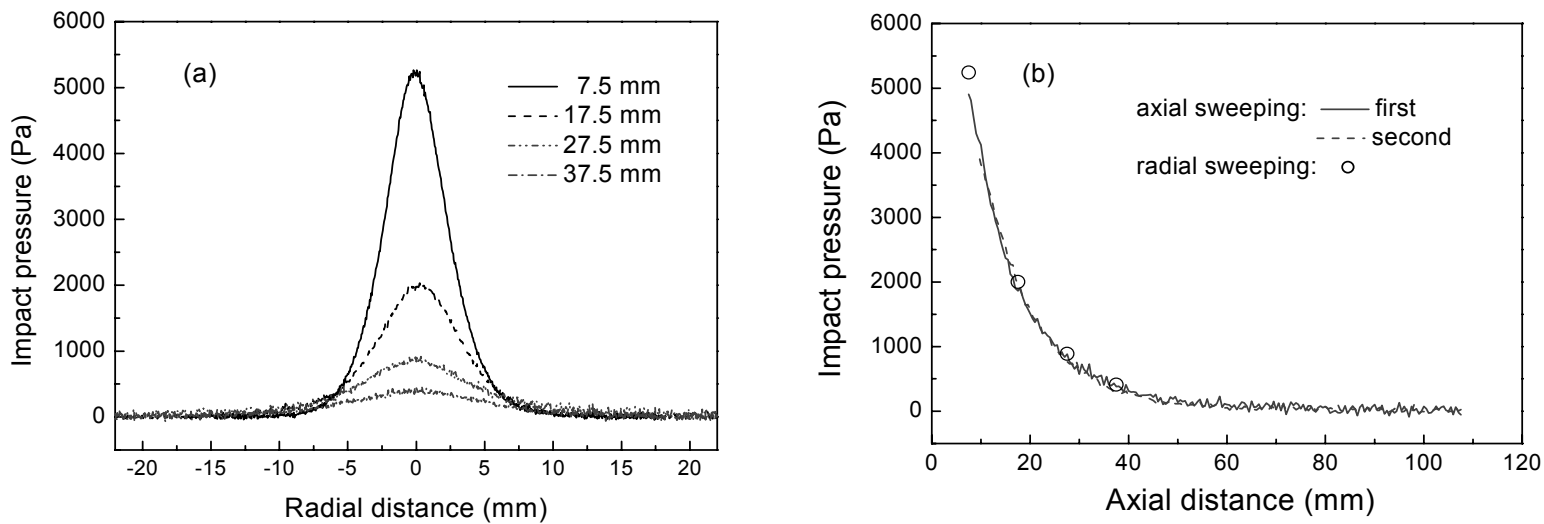

FIGURE 4. Radial (a) and axial (b) distributions of the measured impact pressure with $\mathrm{H}_{2}: \mathrm{N}_{2}=2: 1$ as the propellant at feeding rate of $35.7 \mathrm{mg} / \mathrm{s}$ and input power of $900 \mathrm{~W}$. Markers in (a) indicate the distance from nozzle exit.

Integrated impact pressure of each measuring plane across the plume axis agrees quite well with the platemeasured thrust, when the probe is scanned along the plume radial direction at a suitable axial distance within 15-25 $\mathrm{mm}$ from the thruster nozzle exit. The flow and expansion condition in the nozzle could be affected when the probe is set near the nozzle exit, and when the probe is too far away, the signal is too weak to provide an accurate measurement owing to the limitation of the precision and sensitivity of the pressure sensor attached to the probe.

Fig. 2 (a) indicates that the thruster efficiency is over $40 \%$ of the input power. According to the general estimation [6], the exhaust heat loss is lower than $15 \%$ of the input power, i.e. $129 \mathrm{~W}$, by which the average temperature of exhaust gas is evaluated $[7,8]$ to be lower than $1550 \mathrm{~K}$. At this temperature and chamber pressure of $10 \mathrm{~Pa}$, the $\mathrm{H}_{2}: \mathrm{N}_{2}=2: 1$ gas mixture has its sound-velocity of about $1240 \mathrm{~m} / \mathrm{s}[7,8]$. That is, the plume flow is in the supersonic state, because its specific impulse shown in Fig. 2 (a) is over $4000 \mathrm{~m} / \mathrm{s}$. In Fig.4, however, there is no evidence of a shock wave with the flow impacting on the probe head at different places in the plume. The mean free path of the gas particle at $1550 \mathrm{~K}$ and $10 \mathrm{~Pa}$ is about $4.6 \mathrm{~mm}$ that is much larger than $0.9 \mathrm{~mm}$ of the hole on the probe for impact pressure measurement. The rarefied-gas dynamic effect should be considered at the high temperature and low pressure in analyzing the experimental phenomena in the plume flow.

\section{SUMMARY}

The thrust decreases with increasing nozzle temperature at fixed input power and propellant feeding rate, which indicates that the high nozzle temperature could adversely affect the conversion from enthalpy of high temperature 
gas to kinetic energy for thrust creation. Compared with the estimated average gas-temperature of values lower than $3000 \mathrm{~K}$, the electron temperature is around $20000 \mathrm{~K}$, this means that the plume flow deviates evidently from the LTE condition. Measurement results of the impact pressure distribution in the plume flow suggest that the rarefiedgas dynamic effect should be considered under the high temperature and low-pressure working condition in analyzing the experimental phenomena.

\section{ACKNOWLEDGMENTS}

This work is supported by National Natural Science Foundation of China (Nos. 50836007, 10621202).

\section{REFERENCES}

1. Fred C. Wilson, "Recent Advances in Satellite Propulsion and Associated Mission Benefits", AIAA-2006-5307.

2. K. Toki, H. Kuninaka, Y. Shimizu and K. Kuriki, "Accomplishment and prospect of ISAS electric propulsion”, Acta Astronautica, Vol.50 (5), pp. 285 - 294, (2002).

3. John Slough and J..J. Ewing, "Microarcjet Microthruster for Nanosat Applications", AIAA 2007-5181.

4. J. M. Fife, D. R. Bromaghim, D. A. Chart, W. A. Hoskins, C. E. Vaughan and L. K. Johnson, "Orbital performance measurements of air force electric propulsion space experiment ammonia arcjet", J Propulsion and power, Vol.18 (4), pp. 749-753, (2002).

5. Q. E. Walker, N. Gascon, M. A. Cappelli, W. A. Hargus Jr. and J. A. Schiling, “Arcjet neutralization of hall thrusters, Part 2: experimental demonstration", J Spacecraft and Rockets, Vol.41 (6), pp. 1023-1030, (2004).

6. G. W. Butler, R. J. Cassady, "Directions for Arcjet technology development", J. Propulsion and Power, Vol.12 (6), pp. 10261034, (1996)

A. B. Murphy, "Transport coefficients of hydrogen and argon-hydrogen plasmas", Plasma Chemistry and Plasma Processing, Vol. 20 (3), pp. 279-297, (2000).

7. B. Murphy, C. J. Arundell, "Transport-coefficients of argon, nitrogen, oxygen, argon-nitrogen, and argon-oxygen plasmas", Plasma Chemistry and Plasma Processing, Vol. 14 (4), pp. 451-490, (1994). 